\title{
Neutrophil unsaturated fatty acid release by GM-CSF is impaired in cystic fibrosis
}

Elena Bravo ${ }^{1 *}$, Mariarosaria Napolitano ${ }^{1}$, Sara Benedetti Valentini ${ }^{2}$, Serena Quattrucci $^{2}$

\begin{abstract}
Dysregulated inflammation in cystic fibrosis (CF) is attributed to an altered production of inflammatory mediators derived from polyunsaturated lipids. In comparison to the arachidonic acid (AA) cascade, little is known about the modulation of docosahexaenoic acid (DHA) membrane release. We compared data on neutrophil DHA- and AArelease from both control $(C T)$ and patients with $C F$ using $\left[{ }^{3} \mathrm{H}\right] \mathrm{AA}$ or $\left[{ }^{14} \mathrm{C}\right] \mathrm{DHA}$ as a markers for, respectively, AA and DHA- release. Granulocyte-macrophage-colony stimulating factor stimulated DHA release from $\mathrm{CT}$, but not CF, neutrophils. Comparison showed that both $\left[{ }^{14} \mathrm{C}\right] \mathrm{DHA}$ and $\left[{ }^{3} \mathrm{H}\right] \mathrm{AA}$ liberated after stimulation was higher in $\mathrm{CT}$ than in CF neutrophils. Since bioactive mediators derived from DHA are resolving factors and those derived from AA are both pro- and anti- inflammatory, these results suggest that CF is associated with a reduction of the release of PUFA-precursors of lipooxygenated resolving mediators. This leads to the hypothesis that defects in the resolving factors production could contribute to the inflammatory dysregulated processes in CF. Furthermore, the methodology used may help to improve knowledge on the regulation and resolution of inflammation.
\end{abstract}

\section{Introduction}

Generation of inflammatory mediators is regulated by cytokines and factors released in the early phase of inflammatory and infectious processes. The precursors of bioactive lipid mediators are the polyunsaturated fatty acids (PUFA) released from membrane phospholipids. Earlier studies of bioactive lipids introduced the concept that arachidonic acid [20:4, n6; AA] released from membrane phospholipids by cytosolic phospholipase A2 (cPLA2) is transformed to several series of potent bioactive eicosanoids: prostaglandins, leukotrienes and lipoxins [1]. In more recent years, novel enzymatic oxygenated products generated in vivo were identified in pathways initiated from the precursors eicosapentaenoic acid and docosahexaenoic acid (C22:6 n3; DHA). These new families of compounds contribute functionally to the resolution of inflammation [2-4]. As the discovery of these molecules is relatively recent and the direct analyses of these compounds requires Liquid Chromatography with Tandem Mass Spectrometry Detection [3], most of the available studies have been focused the regulation of AA cascade, while the modulation of DHA metabolism has been poorly

\footnotetext{
* Correspondence: elena.bravo@iss.it

'Department of Cell Biology and Neurosciences, Istituto Superiore di Sanità, Viale Regina Elena, 199 - 00161 Roma, Italy

Full list of author information is available at the end of the article
}

investigated and, as a consequence, the mechanisms modulating DHA release are largely unknown.

Knowledge of these mechanisms could be particularly important for Cystic Fibrosis (CF) patients. CF is the most common lethal autosomal recessive hereditary disease in Caucasians and it is due to dysfunction of the cystic fibrosis transmembrane conductance regulator gene. The basic defect results in secondary pulmonary infection and an excessive neutrophil-driven inflammatory response which are responsible for most of the morbidity and mortality in these patients [5]. The genetic defect lead also to pancreatic insufficiency, and CF-related gastrointestinal manifestations [6].

$\mathrm{CF}$ is associated with an imbalance in the ratio of essential PUFA due to a decreased levels of linoleic and docosahexaenoic acid (n3C22:6; DHA) and to a variable excess of arachidonic acid (n6 C20:4; AA) with respect to DHA [7].

Since in a previous study we showed in CF a lower neutrophil AA-generation in response to lipopolysaccharide (LPS) [8], in this study we aimed to investigate the modulation of DHA release in CF neuttrophils using a similar approach to that used to elucidate the regulation of AA metabolism, and in particular:

a. to study the release of DHA and AA from neutrophils in response to granulocyte-macrophage-colony stimulating factor (GM-CSF) challenge; 
b. to compare the DHA and AA release between neutrophils isolated from control subjects (CT) and CF patients.

\section{Materials and methods}

Arachidonic acid-5,6,8,9,11,12,14,15- ${ }^{3} \mathrm{H}(\mathrm{n})$ (180-240Ci/ mmol), 4,7,10,13,16,19-Docosahexaenoic acid-1- ${ }^{14} \mathrm{C}$ (40-60 $\mathrm{mCi} / \mathrm{mmol})$, and various classes of products were purchased from Sigma Chemical Company (St. Louis, MO, USA). Medium and supplementing factors were obtained from Hyclone Europe Ltd (Sial, Rome, Italy). Dextran T-70 was obtained from Pharmacia Pfizer Italy. GM-CSF was purchased from R\&D Systems Europe Ltd (Space Import Export S.r.l, Milan, Italy).

The study was approved by the Ethical Committee of the University La Sapienza. Written consent was obtained by patients and controls. $15 \mathrm{CF}$ patients and 18 $\mathrm{CT}$, with an average age of $27 \pm 7$ and $28 \pm 7$ years, respectively, were enrolled in the study. Only non smokers, or subjects that had not smoked for at least 1 year, were admitted to the study. Diagnosis of CF was confirmed by at least two abnormal sweat tests. The CF genotype and general characteristics of the patients are reported in Table 1 . All patients were in a stable medical condition, under standard CF therapies such as pancreatic enzyme and vitamin supplementation and did not have acute infection (negative $\mathrm{C}$-reactive protein). None of them were taking corticosteroids therapy. None of CT subjects were on pharmacologic therapies and/or dietary polyunsaturated fatty acids (PUFA) supplementation.

Neutrophils were isolated from blood samples collected in EDTA according to Boyum [9]. After sedimentation in 3\% dextran, the leukocyte-enriched pellet was layered over a Histopaque $1.077 \mathrm{~g} / \mathrm{ml}$ and centrifuged at $400 \times g$ for $40 \mathrm{~min}$. Residual erythrocytes were lysed. The purity of CD16+ neutrophils (phycoerythrin conjugated CD16 and isotype-matched Ig from Becton Dickinson, Milan, Italy) was greater than $90 \%$.

The first step in the generation of biologically important eicosanoids in human neutrophils is AA release from membrane phospholipids by cytosolic phospholipase A2 (cPLA2) [10]. Since AA competes with DHA for the same enzymes and for the site of esterification at the sn- 2 position of phospholipids, to study $\left[{ }^{14} \mathrm{C}\right] \mathrm{DHA}$ and $\left[{ }^{3} \mathrm{H}\right] \mathrm{AA}-$ release, we adapted the method reported by DiPersio et al. [9]. Neutrophils PUFA release was stimulated with GM-CSF at the concentration of $0.2 \mathrm{nM}$. These conditions have been shown to be a suitable stimulation for these tests [11]. Neutrophils, at a density of $3 \times 10^{6}$ cells $/ \mathrm{ml}$ in RPMI containing $0.3 \%$ bovine serum albumin (BSA), were radiolabelled with $\left[{ }^{14} \mathrm{C}\right] \mathrm{DHA}(0.4$ $\mu \mathrm{Ci} / \mathrm{ml})$ or $\left[{ }^{3} \mathrm{H}\right]-\mathrm{AA}(2 \mu \mathrm{Ci} / \mathrm{ml})$ for $3 \mathrm{~h}$ at $23^{\circ} \mathrm{C}$. After labelling and washing, the $\left[{ }^{14} \mathrm{C}\right] \mathrm{DHA}$ or $\left[{ }^{3} \mathrm{H}\right] \mathrm{AA}$ release was tested in RPMI $0.3 \%$ BSA in resting (NT) cells or in cells challenged with $0.2 \mathrm{nM}$ GM-CSF. After $30 \mathrm{~min}$, duplicate samples of $200 \mu \mathrm{l}$ centrifuged medium were assayed for radioactivity by liquid scintillation counting. Radioactivity associated with neutrophils was counted after cell lysis with $200 \mu \mathrm{l}$ of distilled water. Extracellular $\left[{ }^{14} \mathrm{C}\right] \mathrm{DHA}$ and $\left[{ }^{3} \mathrm{H}\right] \mathrm{AA}$-release is expressed as a percentage of the total radioactivity incorporated by the cells. Total radioactivity incorporated into neutrophils takes account of the activity released into the medium. Each experimental point was performed in duplicate.

Plasma fatty acid analysis was performed by gas chromatography [12]. After lipid extraction and acid catalyzed

Table 1 Cystic fibrosis patient characterisation

\begin{tabular}{|c|c|c|c|c|c|c|}
\hline Patient & Age & Sex & Genotype & $\mathrm{BMI}^{\mathrm{a}}(\mathrm{Kg} / \mathrm{m})$ & Diabetes & $\mathrm{FEV} 1^{\mathrm{b}}(\mathrm{Lt})$ \\
\hline 1 & 20 & $F$ & DF508/852del22 & 20,4 & NO & $2,19(75 \%)$ \\
\hline 2 & 40 & M & G542X/UN & 20,7 & NO & $0,49(14 \%)$ \\
\hline 3 & 33 & $F$ & DF508/1717-1GToA & 21,0 & YES & $2,68(98 \%)$ \\
\hline 4 & 25 & $F$ & G542X/N1303K & 17,0 & YES & $0,62(22 \%)$ \\
\hline 5 & 22 & $M$ & DF508/L732X & 20,0 & YES & $1,23(31 \%)$ \\
\hline 6 & 34 & $M$ & UN/UN & 18,0 & YES & $0,63(15 \%)$ \\
\hline 7 & 27 & $F$ & N1303K/N1303K & 15,0 & YES & $0,65(20 \%)$ \\
\hline 8 & 33 & $F$ & N1303K/UN & 20,0 & YES & $0,53(20 \%)$ \\
\hline 9 & 26 & $F$ & DF508/DF508 & 19,0 & YES & $1,04(35 \%)$ \\
\hline 10 & 36 & $M$ & G551D/621+1GtoT & 21,6 & $\mathrm{NO}$ & $1,61(37 \%)$ \\
\hline 11 & 21 & $\mathrm{~F}$ & DF508/DF508 & 16,3 & NO & 1,35 (38\%) \\
\hline 12 & 15 & $F$ & DF508/UN & 18,3 & $\mathrm{NO}$ & $1,05(38 \%)$ \\
\hline 13 & 27 & $F$ & DF508/DF508 & 22,5 & $\mathrm{NO}$ & $1,39(45 \%)$ \\
\hline 14 & 21 & $F$ & DF508/DF508 & 19,4 & $\mathrm{NO}$ & $0,80(27 \%)$ \\
\hline 15 & 36 & $M$ & DF508/G542X & 21,9 & YES & $1,35(46 \%)$ \\
\hline
\end{tabular}

${ }^{\mathrm{a}}$ BMI: Body Mass Index; ${ }^{\mathrm{b}}$ Forced Expiratory Volume in 1 Second 
transesterification, plasma fatty acid methyl esters were analyzed by gas liquid chromatography in a HewlettPackard 5890 Series II gas chromatograph equipped with a flame ionization response detector, a capillary column OmegawaxiM $320(30 \mathrm{~m} \times 0.32 \mathrm{~mm})$ and a $0.25 \mathrm{~mm}$ film (Supelco, Inc.). Heptadecanoic acid (C17:0) was used as internal standard.

Values are expressed in means \pm SD. Statistical analysis and correlation analysis was performed with GraphPad Instat Ver. 4.03 software. The within group differences were assessed by a paired sample paradigm by Wilcoxon matched pairs test. The comparison between the two independent groups $\mathrm{CT}$ and $\mathrm{CF}$ data was performed either by nonparametric one-way ANOVA (KruskalWallis Test) using Dunn's Multiple Comparisons test as post-test or by unpaired t test with Welch correction. Pearson product moment correlation coefficient was used to evaluate the correlation between different variables.

\section{Results}

Gas-chromatographic analysis showed that the percentage of AA $(n=15)$ and DHA $(n=18)$ relative to the total fatty acid content of plasma were, respectively, $7.12 \pm 1.39 \%$ and $1.67 \pm 0.81 \%$ in CF patients and $6.72 \pm 2.28 \%$ and $1.76 \pm 0.79 \%$ in the $\mathrm{CT}$ group, without differences between the groups. However, as expected in these patients, the plasma AA/DHA molar ratio $(4.87 \pm 2.42$ and $3.60 \pm 0.81$ in $\mathrm{CF}$ and $\mathrm{CT}$ group, respectively) was significantly higher in $\mathrm{CF}(\mathrm{P}<0.05)$ with respect to $\mathrm{CT}$.

The $\left[{ }^{14} \mathrm{C}\right]$ DHA release (Table 2) from the membrane by resting CF neutrophils was not significantly different than CT cells. However, $\left[{ }^{14} \mathrm{C}\right] \mathrm{DHA}$ release was increased upon stimulation with GM-CSF in CT neutrophils, but was scarcely modulated in the CF group. The differences, in fact, between $\left[{ }^{14} \mathrm{C}\right] \mathrm{DHA}$ release in NT and GM-CSF conditions were statistically different in the CT group, but not in the $C F$ group $(\mathrm{P}<0.002$ and $\mathrm{P}=0.09$ in $\mathrm{CT}$ and $\mathrm{CF}$, respectively) and consequently, release was significantly higher in $\mathrm{CT}$ as compared to $\mathrm{CF}$ cells after GM-CSF stimulation (Table 2). In both CF and CT groups, $\left[{ }^{14} \mathrm{C}\right] \mathrm{DHA}$ release by resting neutrophils was not

Table 2 Release of DHA by neutrophils

\begin{tabular}{ccc}
\hline \multicolumn{3}{c}{$\begin{array}{c}\text { Neutrophils }\left[^{14} \mathrm{C}\right] \mathrm{DHA} \text { release (\%) } \\
\text { Mean } \pm \text { SD (n) }\end{array}$} \\
& NT & GM-CSF \\
\hline CT & $11.1 \pm 6.3(18)^{a}$ & $15.1 \pm 6.9(18)^{b}$ \\
CF & $9.9 \pm 8.1(15)$ & $8.3 \pm 4.4(15)$ \\
\hline
\end{tabular}

a CT: NT vs GM-CSF, $p<0.002$

${ }^{\mathrm{b}} \mathrm{GM}-\mathrm{CSF}$ : CT vs CF, $\mathrm{p}<0.05$.

The release of $\left[{ }^{14} \mathrm{C}\right] \mathrm{DHA}$ into the medium by neutrophils isolated from control subjects (CT) and patients with cystic fibrosis (CF) was measured in resting cells (NT) and after stimulation with GM-CSF $(0.2 \mathrm{nM})$. Data are expressed as a percentage of the total radioactivity incorporated into the cells.
Table 3 Release of AA by neutrophils

\begin{tabular}{ccc}
\hline \multicolumn{3}{c}{$\begin{array}{c}\text { Neutrophils }\left[^{3} \mathrm{H}\right] \mathrm{AA} \text { release (\%) } \\
\text { Mean } \pm \text { SD (n) }\end{array}$} \\
$\mathbf{N T}$ & GM-CSF \\
\hline $\mathrm{CT}^{a}$ & $6.3 \pm 4.8(16)$ & $10.8 \pm 5.7(16)^{b}$ \\
$\mathbf{C F}$ & $4.1 \pm 3.3(15)$ & $5.4 \pm 2.0(15)$ \\
\hline
\end{tabular}

${ }^{a}$ CT: NT vs GM-CSF, $p<0.01$

${ }^{\mathrm{b}} \mathrm{GM}$-CSF: CT vs CF, $\mathrm{p}<0.02$

The release of $\left.{ }^{3} \mathrm{H}\right] \mathrm{AA}$ into the medium by neutrophils isolated from control subjects (CT) and patients with cystic fibrosis (CF) was measured in resting cells (NT) and after stimulation with GM-CSF $(0.2 \mathrm{nM})$. Data are expressed as a percentage of the total radioactivity incorporated into the cells.

correlated with the release upon GM-CSF stimulation, or with the proportion of DHA or AA in the plasma.

In CT neutrophils, cytokine stimulation induced a strong increase of the release of $\left[{ }^{3} \mathrm{H}\right] \mathrm{AA}$ (Table 3) with respect to resting cells (NT vs GM-CSF: $\mathrm{P}<0.001$ ), but $\mathrm{CF}$ neutrophils were not responsive to the stimulation as there was no significant change in $\left[{ }^{3} \mathrm{H}\right] \mathrm{AA}$ release. In fact, the mean of the $\left[{ }^{3} \mathrm{H}\right]$ AA released after GM-CSF challenging from $\mathrm{CF}$ neutrophils was markedly lower in comparison to that from CT cells (GM-CSF: CF vs CT: $\mathrm{P}<0.02)$. There were no differences in either $\left[{ }^{14} \mathrm{C}\right] \mathrm{DHA}$ or $\left[{ }^{3} \mathrm{H}\right]$ AA release between CF patient with $(n=8)$ and without $(\mathrm{n}=7)$ diabetes.

There was a positive correlation between the $\left[{ }^{3} \mathrm{H}\right] \mathrm{AA}$ released in resting conditions and after GM-CSF challenge, and this was markedly stronger in the CT group $(r=0.86, p<0.0005)$ in comparison to the CF patients $(\mathrm{r}=0.59, \mathrm{p}<0.05)$. Also, in the control group, but not the $\mathrm{CF}$ group, the neutrophil $\left[{ }^{3} \mathrm{H}\right] \mathrm{AA}$ release positively correlated with the AA plasma content both in resting $(\mathrm{r}=$ $0.61, \mathrm{p}<0.02)$ and stimulated $(\mathrm{r}=0.59, \mathrm{p}<0.05)$ neutrophils.

Evaluation of the relationship between the radioactive tests showed that $\left[{ }^{14} \mathrm{C}\right] \mathrm{DHA}$ and the $\left[{ }^{3} \mathrm{H}\right] \mathrm{AA}$ release were correlated, in resting condition in $\mathrm{CF}$ neutrophils $(\mathrm{r}=0.80, \mathrm{p}<0.003)$, and after the stimulation with GM-CSF in CT cells $(\mathrm{r}=0.77, \mathrm{P}<0.03)$.

\section{Discussion}

AA and the mobilisation of its early metabolites can be monitored by the release of previously radiolabelled AA in the membrane pool. This method, described more than 20 years ago for the measurement of the proinflammatory precursors release by neutrophil $[11,13,14]$, is still widely used in several fields to test membrane mobilisation of the mediator precursors [15-17], but, to the author's knowledge, it has never been used to study modulation of the DHA release. In this work we used $\left[{ }^{3} \mathrm{H}\right] \mathrm{AA}$ or $\left[{ }^{14} \mathrm{C}\right] \mathrm{DHA}$ as a marker for, respectively, the AA and the DHA-related products released from the membrane after neutrophil activation. 
GM-CSF was found to elicit a significant enhancement of $\left[{ }^{3} \mathrm{H}\right] \mathrm{AA}$ released from $\mathrm{CT}$, but not $\mathrm{CF}$ neutrophils (Table 3). In CT neutrophils, the AA cascade triggered by GM-CSF produced a release of $\left[{ }^{3} \mathrm{H}\right] \mathrm{AA}$ significantly higher than that observed in resting cells $(+71 \%)$, and also than that found in GM-CSF-treated CF neutrophils $(+100 \%)$. In contrast, there was no significant increase in AA-derived precursors released by the CF cells in response to specific neutrophil stimulation.

In the case of DHA, our results show that regulation of its liberation from neutrophils is also modulated in CT subjects differently than in CF patients. Treatment with GM-CSF induced a significant increase of $\left[{ }^{14} \mathrm{C}\right]$ DHA liberated from CT neutrophils (Table 2). Conversely, cells derived from CF patients responded to GM-CSF challenge with a slight reduction of $\left[{ }^{14} \mathrm{C}\right] \mathrm{DHA}$ recovered into the medium. As mediators derived from DHA cascade induce the production of resolvins and protectins [2-4], families of compounds with resolving and anti-inflammatory activity, the lack of response to GM-CSF in CF patients suggests that the liberation of PUFA precursors of resolving mediators derived from DHA is markedly impaired in CF neutrophils.

The concept of defective production of mediator precursors in $\mathrm{CF}$ is supported by correlation analysis, as the releases of the $\left[{ }^{14} \mathrm{C}\right] \mathrm{DHA}$ and the $\left[{ }^{3} \mathrm{H}\right] \mathrm{AA}$ correlate in CF group in resting condition, whereas in CT group the same correlation is observed only after stimulation with GM-CSF, indicating that both the basal response and the mechanisms regulating precursors liberation are altered in the CF patients. Furthermore, both in resting and stimulated CT neutrophils, the $\left[{ }^{3} \mathrm{H}\right] \mathrm{AA}$ released is correlated with plasma AA content, while this relationship is totally lacking in CF neutrophils, suggesting that other factors play a greater role than lack/availability of AA in the regulation of the inflammatory response in CF neutrophils. In addition, although not definitive, our results suggest that, in contrast to $\left[{ }^{3} \mathrm{H}\right] \mathrm{AA}$ release, $\left[{ }^{14} \mathrm{C}\right]$ DHA release is not correlated with the plasma proportion of either AA or DHA, suggesting that it may be difficult to regulate resolvins and protectins synthesis by modifications of availability of DHA in CF as well control subjects.

In agreement with the data that CF-related diabetes represents the most common co-morbidity in this disease [18], about $50 \%$ of CF subject were diabetics. Diabetes in CF patients depends on the basic genetic defect and shows important differences with respect to both type 1 and type 2 diabetes [18]. We found that, although disturbances in AA cascade are common in type 2 diabetes [19], there were no differences in PUFA membrane release in CF-related diabetes.

The dysregulated inflammatory response in CF is commonly considered excessive [5], and the abnormalities in
AA release in CF patients have been attributed to an exaggerated production of proinflammatory mediators such as leukotrienes and prostaglandins, which exacerbated the lung infection in these patients $[5,13,14]$. However, in 2004 Karp et al. [20] reported an important defect in lipoxin and anti-inflammatory activity in CF airways, and suggested that in CF a deficiency of resolving factors prevents resolution of lung inflammation and impedes healing. Our results indicate that $\mathrm{CF}$ is associated with both an impaired regulation by GM-CSF of the release of PUFA from the membrane and decreased liberation of DHA and AA precursors, suggesting that the generation of mediators derived from DHA and AA in CF is insufficient, rather than excessive. In particular, as lipooxygenated products derived from DHA have a major function in infection termination and healing, the lack of response to GM-CSF may be directly related to an impaired resolution of infections [21]. Furthermore, the DHA deficiency associated with CF [7] may worsen the liberation of appropriate amount of DHA-derived healing factors.

In conclusion, although future studies are necessary to clarify the underlying mechanisms of altered PUFA delivery from CF neutrophils, the preliminary results of this study indicate a major defect in DHA delivery by neutrophils delivery in $\mathrm{CF}$ and suggests a useful methodological approach for the study of DHA metabolism, which may help to monitor the early stages of resolving factor production in response to different therapeutic interventions.

\section{List of abbreviations}

CF: cystic fibrosis; AA: arachidonic acid; DHA: docosahexaenoic acid; GM-CSF: Granulocyte-macrophage-colony stimulating factor; PUFA: polyunsaturated fatty acids;

\section{Acknowledgements}

Our gratitude to La Lega Italiana per la lotta alla Fibrosi Cistica which has supported this work. We are thankful for Dr. Sabrina Zullo and Dr. Vincenza Papa for their help to the work. We like to thank Prof. KM Botham for language revision of the manuscript.

\section{Author details}

'Department of Cell Biology and Neurosciences, Istituto Superiore di Sanità, Viale Regina Elena, 199 - 00161 Roma, Italy. ${ }^{2}$ Centro Fibrosi Cistica di Riferimento Regione Lazio - Department of Pediatrics - University "La Sapienza", Viale Regina Elena 324 - 00161 Roma, Italy.

\section{Authors' contributions}

EB and SQ designed the study, MN carried out the experiments and analysis of the data, SQ and SBV responsible for any aspect related to the patients, EB drafted the paper. All the authors contributed to the interpretation and discussion of the results related to their part of the work and critically revised the paper.

\section{Competing interests}

The authors declare that they have no competing interests.

Received: 30 September 2010 Accepted: 8 November 2010 Published: 8 November 2010 


\section{References}

1. Samuelsson B, Dahlén SE, Lindgren JA, Rouzer CA, Serhan CN: Leukotrienes and lipoxins: structures, biosynthesis, and biological effects. Science 1987, 237:1171-1176.

2. Serhan CN, Clish CB, Brannon J, Colgan SP, Chiang N, Gronert K: Novel functional sets of lipid-derived mediators with antiinflammatory actions generated from omega-3 fatty acids via cyclooxygenase 2-nonsteroidal antiinflammatory drugs and transcellular processing. J Exp Med 2002, 192:1197-1204.

3. Hong S, Gronert K, Devchand PR, Moussignac RL, Serhan CN: Novel docosatrienes and 17S-resolvins generated from docosahexaenoic acid in murine brain, human blood and glial cells. Autacoids in antiinflammation. J Biol Chem 2003, 278:14677-14887.

4. Ariel A, Serhan $\mathrm{CN}$ : Resolvins and protectins in the termination program of acute inflammation. Trends Immunol 2007, 28:176-183.

5. Berger M: Inflammation in cystic fibrosis: a vicious cycle that does more harm than good? Clin Rev Allergy 1991, 9:119-142.

6. Haber1 HP: Cystic Fibrosis in Children and Young Adults: Findings on Routine Abdominal Sonography. Am J Roentgenol 2007, 189:89-99.

7. Freedman SD, Blanco PG, Zaman MM, Shea JC, Ollero M, Hopper IK, Weed DA, Gelrud A, Regan MM, Laposata M, Alvarez JG, O'Sullivan BP: Association of cystic fibrosis with abnormalities in fatty acid metabolism. N Engl J Med 2004, 350:560-569.

8. Quattrucci S, Napolitano M, Valentini SB, Giuliani A, Bravo E: Neutrophil generation of inflammatory precursors is not modulated by docosahexaenoic acid. Inflamm Res 2009, 58:677-685.

9. Boyum A: Isolation of mononuclear cells and granulocytes from human blood. Isolation of monuclear cells by one centrifugation, and of granulocytes by combining centrifugation and sedimentation at $1 \mathrm{~g}$. Scand J Clin Lab Invest Suppl 1968, 97:77-89.

10. Leslie CC: Properties and regulation of cytosolic phospholipase A2. J Biol Chem 1997, 272:16709-16712

11. DiPersio JF, Billing P, Williams R, Gasson JC: Human granulocytemacrophage colony-stimulating factor and other cytokines prime human neutrophils for enhanced arachidonic acid release and leukotriene B4 synthesis. J Immunol 1988, 140:4315-4322.

12. Bravo E, Cantafora A, Marinelli T, Avella M, Mayes PA, Botham KM: Differential effects of chylomicron remnants derived from corn oil or palm oil on bile acid synthesis and very low density lipoprotein secretion in cultured rat hepatocytes. Life Sci 1996, 59:331-337.

13. Carlstedt-Duke J, Brönnegard M, Strandvik MB: Pathological regulation of arachidonic acid release in cystic fibrosis: the putative basic defect. Proc Natl Acad Sci USA 1986, 83:9202-9206.

14. Strandvik B, Brönnegerd M, Gilljam H, Carlstedt-Duke J: Relation between defective regulation of arachidonic acid release and symptoms in cystic fibrosis. Scand J Gastroenterol 1988, 23S:1-4.

15. Rossi A, Pergola C, Koeberle A, Hoffmann M, Dehm F, Bramanti P, Cuzzocrea S, Werz O, Sautebin L: The 5-lipoxygenase inhibitor, zileuton, suppresses prostaglandin biosynthesis by inhibition of arachidonic acid release in macrophages. Br J Pharmacol 2010, 161:555-570

16. Wong RK, Pettit Al, Quinn PA, Jennings SC, Davies JE, Ng LL: Advanced glycation end products stimulate an enhanced neutrophil respiratory burst mediated through the activation of cytosolic phospholipase A2 and generation of arachidonic acid. Circulation 2003, 108:1858-1864.

17. Sciullo EM, Dong B, Vogel CF, Matsumura F: Characterization of the pattern of the nongenomic signaling pathway through which TCDDinduces early inflammatory responses in U937 human macrophages. Chemosphere 2009, 74:1531-1537.

18. O'Riordan SMP, Robinson PD, Donaghue KC, Moran A: Management of cystic fibrosis-related diabetes. Pediatric Diabetes 2008, 9(Part I):338-344.

19. Natarajan R, Nadler JL: Lipid inflammatory mediators in diabetic vascular disease. Arterioscler Thromb Vasc Biol 2004, 24:1542-1548.

20. Karp CL, Flick LM, Park KW, Softic S, Greer TM, Keledjian R, Yang R, Uddin J, Guggino WB, Atabani SF, Belkaid Y, Xu Y, Whitsett JA, Accurso FJ, WillsKarp M, Petasis NA: Defective lipoxin-mediated anti-inflammatory activity in the cystic fibrosis airway. Nature Immunol 2004, 5:388-392.

21. Takai D, Nagase T, Shimizu T: New therapeutic key for cystic fibrosis: a role for lipoxins. Nature Immunol 2004, 5:357-358.

\section{doi:10.1186/1476-511X-9-129}

Cite this article as: Bravo et al: Neutrophil unsaturated fatty acid release by GM-CSF is impaired in cystic fibrosis. Lipids in Health and Disease 2010 9:129.

\section{Submit your next manuscript to BioMed Central and take full advantage of:}

- Convenient online submission

- Thorough peer review

- No space constraints or color figure charges

- Immediate publication on acceptance

- Inclusion in PubMed, CAS, Scopus and Google Scholar

- Research which is freely available for redistribution

Submit your manuscript at www.biomedcentral.com/submit
Ciomed Central 